\title{
Greater Superficial Petrosal Nerve Schwannoma: 3 Case Reports and Review of Literature
}

\author{
Khursheed A. Ansari ${ }^{*}, 1$, Girish Menon ${ }^{2}$, Mathew Abraham ${ }^{2}$ and Suresh Nair ${ }^{2}$ \\ ${ }^{I}$ Department of Neurosurgery, Wockhardt Hospitals, The Umrao Institute of Medical Sciences and Research, Mira road, \\ North Bombay, India-401107 \\ ${ }^{2}$ Department of Neurosurgery, Sree Chitra Tirunal Institute for Medical sciences and technology, Trivandrum, Kerala, \\ India-695011
}

\begin{abstract}
Greater superficial petrosal nerve (GSPN) schwannomas are very rare tumors. There are only 15 reports, described so far. In this study the authors discuss the clinical presentation, radiological features, surgical approach, postoperative outcome and follow up of 3 cases of this rare schwannoma of the middle fossa, possibly originating from GSPN together with the review of existing literature. The presenting features were facial paresis in all cases, xerophthalmia in case 1 , and tinnitus in case 2. Imaging studies showed a sub-temporal extradural mass on the anterosuperior aspect of the petrous bone in all cases. All tumors were removed through a subtemporal extradural microsurgical approach. Improvement of facial weakness and xerophthalmia as an end result is characteristic post-operative finding.
\end{abstract}

Keywords: Facial nerve, greater superficial petrosal nerve, middle fossa, schwannoma, xerophthalmia.

\section{INTRODUCTION}

Schwannomas of middle cranial fossa commonly arise from the trigeminal nerve but may arise from facial nerve or greater superficial petrosal nerve (GSPN). GSPN schwannomas, in particular are very rare tumors, with only 15 documented case reports available in literature. We present our experience with 3 cases of petrous temporal based extradural schwannomas possibly GSPN schewannomas, together with the review of existing literature.

\section{CASE 1}

23 year old male presented with decreased lacrimation from right eye followed by deviation of angle of mouth to left side of four month duration without any hearing loss. On examination, lower motor neuron (LMN) facial palsy of House Brackman (HB) grade V was the only finding. Schirmer's test was positive. Head computed tomography (CT) showed an isodense to hypodense extra dural mass in the left middle cranial fossa abutting the antero-superior part of petrous bone extending to geniculate ganglion and laterally till the middle ear. Magnetic resonance imaging (MRI) demonstrated an extra-axial mass iso- to hypointense to brain on $\mathrm{T} 1$ and hyperintense on $\mathrm{T} 2$ weighted images (WI) with heterogenous contrast enhancement measuring $24 \mathrm{~mm} x$ $13 \mathrm{~mm} \times 12 \mathrm{~mm}$ (Fig. 1a, b). He underwent subtemporal extradural middle fossa surgical approach and total excision

*Address correspondence to this author at the Department of Neurosurgery, Wockhardt Hospitals, Unit: The Umrao Institute of Medical sciences and research, Mira road, North Bombay. India - 401107; Tel: +919699674595; E-mail: drkhursheed@ rediffmail.com of the schwannoma. The tumor was eroding the anterosuperior aspect of petrous bone and was abutting the geniculate part of VIIth nerve. Postoperatively his facial palsy improved to HB grad III with xerophthamia. CT brain after 5 year of surgery did not show any recurrence.

\section{CASE 2}

50 year old female presented with complaints of progressive deviation of angle of mouth to right and inability to close left eye completely for the last 8 months. She also had tinnitus in the left ear not associated with any kind of hearing loss for 3 years. On examination she had a left LMN facial palsy of HB grade IV. Cranial contrast CT scan showed a left temporal heterogeneously enhancing mass lesion along the superior surface of petrous bone with evidence of bone erosion. MRI showed heterogenous enhancing $38 \mathrm{~mm} \times 26 \mathrm{~mm} \times 36 \mathrm{~mm}$ extra axial mass lesion occupying the middle cranial fossa indenting in to temporal lobe (Fig. 1c, $\mathbf{d}$ and $\mathbf{e}$ ). Gross total excision of the tumor achieved without disturbing the facial nerve by extradural subtemporal approach. Histopathology was consistent with schwannoma. MRI head, one year after surgery did not show any residual or recurrent tumor (Fig. 1f). She has HB grade II facial palsy, 4 years after surgery.

\section{CASE 3}

26 year old male presented with infrequent right eye blinking with inability to close the right eye completely for the last 6 months. On examination he had HB grade IV facial paresis with normal hearing on audiometry. CT scan showed an eroded cup in the superior aspect of the left petrous bone 


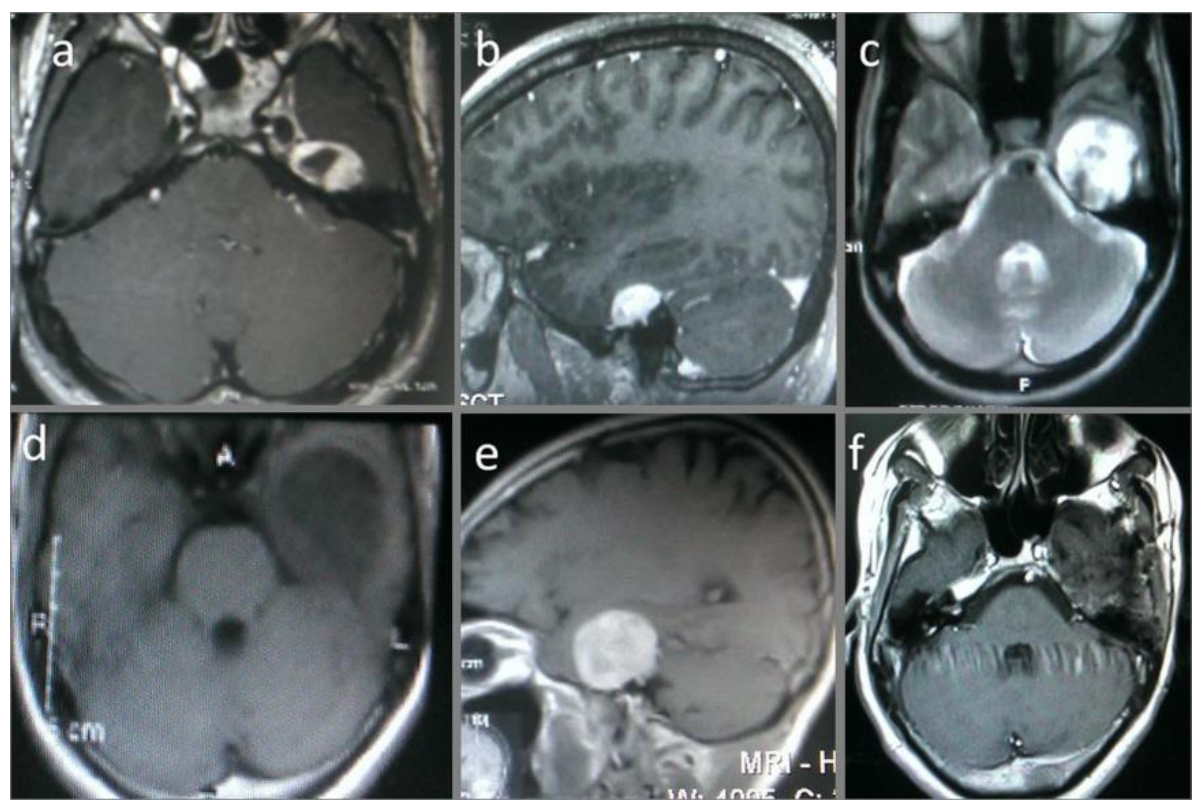

Fig. (1). Gadolinium enhanced contrast MR imges (a) axial and (b) sagittal cut of Case 1 showing heterogenous enhancement of tumor located at antero-superior aspect of petrous temporal bone, with (b) showing enhancing tail at the petrous surface highly suspicious of GSPN schwannoma. (c,d,e and f) are MR images of Case 2, (c) T2WI showing tumor is heterogeneously hyperintense, (d) T1WI showing hypointense tumor, (e) contrast enhaced sagittal image, (f) postoperative contrast enhanced image showing complete clearance of tumor.

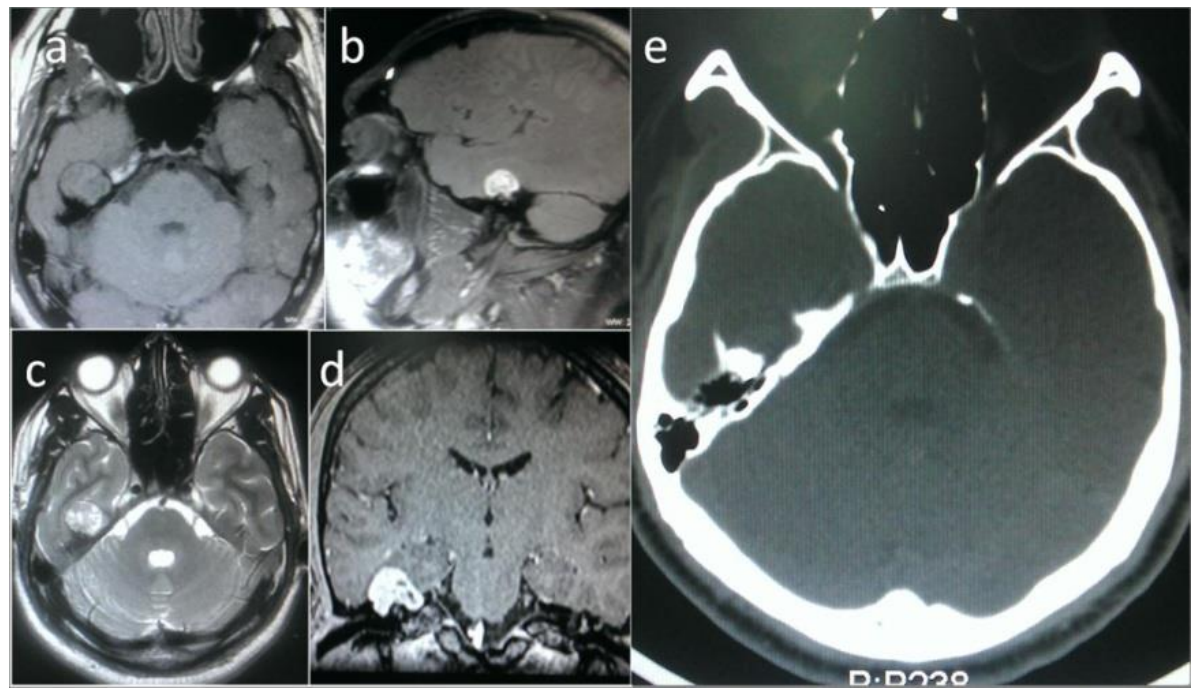

Fig. (2). Case 3 (a) T1WI showing iso-to hypo intense lesion, (b and d) T1 contrast enhanced sagittal and coronal section showing heterogenous enhancement, (c) T2WI showing hetergenously hyperintense tumor located at anterosuperior surface of right petrous bone, (e) axial section bone window showing a cup shape that has been eroded in the superior aspect of the right petrous bone.

filled with a tumor mass (Fig. 2e). On MRI the lesion was hypointense to isointense on T1WI and heterogeneously hyperintense on T2WI measuring $22 \mathrm{~mm}$ x $21 \mathrm{~mm}$ x $21 \mathrm{~mm}$. The tumor enhanced heterogeneously after contrast material injection (Fig. 2 a, b, c and d). A subtemporal extradural surgical approach was used to achieve total excision of the lesion with preservation of facial nerve. She has HB grade III facial weakness at one and half years after surgery.

\section{DISCUSSION}

Facial nerve schwannomas are rare and comprise about $0.8 \%$ of all intrapetrous mass lesions $[1,2,3,4]$. In order of decreasing frequency these schwannomas in petrous bone, can arise from tympanic, vertical, labyrinthine, geniculate, and meatal segment of the facial nerve [5]. In the middle cranial fossa, schwannomas can arise from the geniculate ganglion or GSPN. GSPN schwannomas are extremely rare.

The first branch given off in the facial nerve's course is GSPN, which carries preganglionic parasympathetic fibers (general visceral efferent) from a part of the superior salivatory nucleus or the lacrimal nucleus. These fibers are conveyed by the nervous intermedius to the geniculate ganglion. They pass through the ganglion without synapsing, into the GSPN. GSPN goes forward through the hiatus of the facial canal located on the anterosuperior aspect of the petrous bone (extradurally) to join the deep petrosal nerve 
Table 1. Review of the literature of the GSPN schwannoma.

\begin{tabular}{|c|c|c|c|c|c|c|}
\hline Aurthors and Years & $\begin{array}{l}\text { No of } \\
\text { cases }\end{array}$ & $\begin{array}{l}\text { Age/ } \\
\text { Sex }\end{array}$ & Symptoms and diagnosis & $\begin{array}{c}\text { Surgical } \\
\text { Approach }\end{array}$ & Post-operative outcome & $\begin{array}{l}\text { Follow- } \\
\text { up }\end{array}$ \\
\hline $\begin{array}{c}\text { Tremble and Penfield } \\
1936[20]\end{array}$ & 1 & $42 / \mathrm{M}$ & $\begin{array}{l}\text { Facial weakness, hearing loss, } \\
\text { tinnitus }\end{array}$ & MF-ED & Not mentioned & NA \\
\hline $\begin{array}{c}\text { Kleinsassar and Friedman } \\
1959[19]\end{array}$ & 1 & $19 / \mathrm{F}$ & Facial weakness and hearing loss & MF-ED & No new change & $\begin{array}{c}6 \\
\text { months }\end{array}$ \\
\hline Furlow 1960 [2] & 2 & $\begin{array}{l}48 / \mathrm{M} \\
44 / \mathrm{M}\end{array}$ & $\begin{array}{c}\text { Facial palsy, } \\
\text { Hearing difficulty, } \\
\text { Generalised seizure(in both } \\
\text { cases) }\end{array}$ & $\begin{array}{l}\text { MF-ED } \\
\text { MF-ED }\end{array}$ & $\begin{array}{l}\text { No change } \\
\text { No change }\end{array}$ & $\begin{array}{c}8 \\
\text { months }\end{array}$ \\
\hline Kumon et al. 1999 [13] & 1 & $21 / \mathrm{M}$ & Hearing disturbance & MF-ED & No facial palsy, usefull hearing & 1 year \\
\hline Michel et al. 2000 [10] & 1 & $20 / \mathrm{M}$ & $\begin{array}{c}\text { Vertigo, hearing loss \& Facial } \\
\text { paresis }\end{array}$ & MF-ED & No facial palsy & NA \\
\hline Kinouchi et al $2001[15]$ & 2 & $\begin{array}{l}58 / \mathrm{F} \\
49 / \mathrm{F}\end{array}$ & $\begin{array}{c}\text { Vertigo } \\
\text { Trigeminal nerve affection }\end{array}$ & $\begin{array}{l}\text { MF-ED } \\
\text { MF-ED }\end{array}$ & $\begin{array}{l}\text { Xerophthalmia } \\
\text { No deficits }\end{array}$ & NA \\
\hline Aihara et al. 2001 [7] & 1 & $65 / \mathrm{M}$ & Facial palsy & MF-ED & Facial palsy improving & $\begin{array}{c}6 \\
\text { months }\end{array}$ \\
\hline $\begin{array}{c}\text { Schmidinger et al } 2005 \\
{[11]}\end{array}$ & 1 & $65 / \mathrm{F}$ & Facial palsy and hearing loss & MF-ED & $\begin{array}{l}\text { Facial palsy increased, hearing loss } \\
\text { remained same }\end{array}$ & $\begin{array}{c}6 \\
\text { months }\end{array}$ \\
\hline Mori et al. 2007 [3] & 1 & $50 / \mathrm{M}$ & Hearing loss & MF-ED & No deficits & NA \\
\hline Sade \& Lee 2007 [21] & 1 & $63 / \mathrm{F}$ & Facial palsy and hearing loss & MF-ED & Facial palsy improving, Useful hearing & NA \\
\hline Ayberk G et al. 2008 [1] & 1 & $16 / \mathrm{F}$ & $\begin{array}{c}\text { Double vision, decreased tear } \\
\text { secretion }\end{array}$ & MF-ED & No deficits & 1 year \\
\hline $\begin{array}{l}\text { Amirjamshidi et al. } 2010 \\
\text { [5] }\end{array}$ & 5 & $\begin{array}{r}22 / \mathrm{F} \\
25 / \mathrm{M} \\
28 / \mathrm{M} \\
28 / \mathrm{M} \\
54 / \mathrm{F}\end{array}$ & $\begin{array}{c}\text { HA, seizure } \\
\text { Eye pain } \\
\text { HA, eye pain } \\
\text { Eye pain } \\
\text { HA and hysteria }\end{array}$ & $\begin{array}{l}\text { MF-ED/ID } \\
\text { MF-ED } \\
\text { MF-ED } \\
\text { MF-ED/ID } \\
\text { MF- ED }\end{array}$ & $\begin{array}{c}\text { Facial palsy improving } \\
\text { Facial palsy improving } \\
\text { Xerophthalmia } \\
\text { No deficit } \\
\text { Xerophthamia }\end{array}$ & $\begin{array}{c}1 \text { year } \\
6 \\
\text { months } \\
\text { NA } \\
\text { NA } \\
\text { NA }\end{array}$ \\
\hline Paulis DD et al. 2011 [14] & 1 & $23 / \mathrm{F}$ & Facial palsy, hearing loss & MF-ED/ID & $\begin{array}{l}\text { Facial palsy and hearing loss improved } \\
\text { partially }\end{array}$ & 6 month \\
\hline $\begin{array}{c}\text { Umredkar A et al. } 2011 \\
{[22]}\end{array}$ & 2 & $\begin{array}{l}51 / \mathrm{F} \\
45 / \mathrm{F}\end{array}$ & $\begin{array}{l}\text { HA, Facial palsy, Hearing loss } \\
\text { Hearing loss and facial palsy }\end{array}$ & $\begin{array}{l}\text { MF-ED } \\
\text { MF-ED }\end{array}$ & $\begin{array}{l}\text { No change in facial palsy, hearing } \\
\text { improved } \\
\text { Facial palsy improving, hearing } \\
\text { remained same }\end{array}$ & $\begin{array}{c}1 \text { year } \\
6 \\
\text { months }\end{array}$ \\
\hline Present report & 3 & $\begin{array}{c}23 / \mathrm{M} \\
50 / \mathrm{F} \\
26 / \mathrm{M}\end{array}$ & $\begin{array}{l}\text { Facial palsy, decreased } \\
\text { lacrimation } \\
\text { Facial palsy, tinnitus } \\
\text { Facial palsy }\end{array}$ & $\begin{array}{l}\text { MF-ED } \\
\text { MF-ED } \\
\text { MF-ED }\end{array}$ & $\begin{array}{l}\text { Facial palsy improving, Xerophthalmia } \\
\text { same } \\
\text { Facial palsy improving } \\
\text { Facial palsy improving }\end{array}$ & $\begin{array}{c}5 \text { years } \\
4 \text { years } \\
18 \\
\text { months }\end{array}$ \\
\hline
\end{tabular}

HA headache; HA Headache, MF-ED/ID Middle fossa-extradural/intradural, NA not available

from the carotid sympathetic plexus to form the vidian nerve, or the nerve of the pterygoid canal, which runs to the sphenopalatine ganglion, from where postganglionic fibers proceed to the lacrimal gland. GSPN schwannoma can arise from anywhere along its course.
Average age of presentation of GSPN schwannoma in our study is 39 years and females are more commonly affected. They usually present with facial paresis and hearing loss [6]. Xerophthalmia, although pathognomonic of GSPN schwannoma may not be there in all patients and only present if parasympathetic nerve fibers have been destroyed 
by the tumor [7-11]. In previously reported cases only 6 patients had xerophthalmia [1, 12-14]. Other reported manifestations include diplopia due to abducens nerve palsy [1], trigeminal nerve involvement [15], seizure [12], eye pain, headache etc. One of our patient had xerophthalmia, all three had facial paresis.

On imaging GSPN schwannoma appears as a middle fossa epidural mass extending from facial hiatus to foramen lacerum. Benign-appearing bony scalloping and remodeling of the bony boundaries in the anterosuperior aspect of the petrous bone is usually a characteristic of schwannoma of the GSPN. It can be easily misunderstood by schwannoma originating from geniculate ganglion, which usually causes bulbous enlargement of the geniculate fossa [5, 4, 13]. Therefore, Careful inspection of the skull base and anterosuperior aspect of the temporal bone is mandatory $[8,16]$. It is usually isodense to gray matter with homo- to heterogeneous post-contrast enhancement containing cystic or calcified foci on CT scan [3,6, 16-18]. MRI may show tumor iso- to hypointense relative to gray matter on T1WI and hetero- to homogenously hyperintense on T2WI [1, 4, 19]. Contrast-enhanced MR images usually demonstrate homo- to heterogeneous enhancement. Carotid angiography has been advised if tumor is in close proximity or abutting petrous carotid artery $[1,2,10,13,20]$. In none of our case it deemed necessary.

Middle fossa approach and excision of the tumor is the ideal treatment recommended for this schwannoma. Tumor size and main symptom helps in determining to choose between intra or extra dural subtemporal corridor [5]. Relatively big tumor indenting in to the temporal lobe or seizure as a presenting symptom usually require intradural exploration also. In all of our patient middle fossa extradural approach was selected. The geniculate ganglion and petrous carotid artery should be taken care of during removal of the tumor. Normally GSPN schwannoma doesn't show more proximal involvement than the facial hiatus [21]. None of our lesion extended to cavernous sinus wall which otherwise would have confused the diagnosis with trigeminal schwannoma. We did not require drilling of middle fossa base as tumor had widened and remodelled the bone around it. However Ahihara et al., have described drilling of middle fossa to facilitate tumor removal [7]. During drilling, it is extremely important to know the orientation of middle fossa triangle, lie of petrous carotid artery and labyrinthine structures, and surgeons experience plays a crucial role.

Facial nerve function usually improves following surgery, only in 3 of the previous reported cases it has either deteriorated or remained same as preoperative status [11, 12]. All of our patients showed improvement in facial nerve function. Xerophthalmia is common after surgical excision and patient needs artificial tear drops. Table $\mathbf{1}$ summerises the findings of all previously reported cases of GSPN schwannoma.

\section{CONCLUSION}

GSPN schwannoma is a rare entity and it should be considered as a differential diagnosis in extra-axial enhancing lesions located in the anterosuperior aspect of the petrous bone. They are amenable to total surgical excision and carry a good long term outcome. Early diagnosis and meticulous surgery helps to preserve the function of facial and acoustic nerves. Improvement in facial nerve function after surgery is an indication of such schwannoma being GSPN in origin.

\section{CONFLICT OF INTEREST}

The authors confirm that this article content has no conflict of interest.

\section{ACKNOWLEDGEMENTS}

Declared none.

\section{REFERENCES}

[1] Ayberk G, Ozveren MF, Uzum N, Tosun O, Akcay EK. Cellular schwannoma of the greater superficial petrosal nerve presenting with abducens nerve palsy and xerophthalmia: case report. Neurosurgery 2008; 63: E813-E814.

[2] Furlow LT. The neurosurgical aspect of seventh nerve neurilemmoma. J Neurosurg 1960; 17: 721-35.

[3] Mori R, Sakai H, Kato M, et al. Huge facial nerve schwannoma extending into the middle cranial fossa without facial palsy: case report]. No Shinkei Geka 2007; 35: 591-8, (Jpn).

[4] Wiggins RH III, Harnsberger HR, Salzman KL, Shelton C, Kertesz TR, Glastnbury CM. The many faces of facial nerve schwannoma. AJNR Am J Neuroradiol 2006; 27: 694-9.

[5] Amirjamshidi A, Hashemi SM, Abbassioun K. Schwannoma of the greater superficial petrosal nerve: report of 5 cases. J Neurosurg 2010; 113: 1093-8.

[6] Beskin RR, Eick JJ. Calcified acoustic neuroma. South Med J 1989; 82: 1048-50.

[7] Aihara N, Yamada K, Matzuda F, Murakami S. Neurinoma of the greater superficial petrosal nerve developed acute facial palsy: case report and review of the literature. Skull Base 2001; 11: 77-80.

[8] Furuta S, Hatakeyama T, Zenke K, Nagato S. Huge facial schwannoma extending into the middle cranial fossa and cerebellopontine angle without facial nerve palsy: case report. Neurol Med Chir (Tokyo) 2000; 40: 528-31.

[9] Guntinas-Lichius O, Wagner M, Michel O. Neurinoma of the major petrosus nerve. HNO 1999; 47: 279-82, (Ger).

[10] Michel O, Wagner M, Guntinas-Lichius O. Schwannoma of the greater superficial petrosal nerve. Otolaryngol Head Neck Surg 2000; 122: 302- 303 .

[11] Schmidinger A, Deinsberger W. Greater superficial petrosal nerve schwannoma. Acta Neurochir (Wien) 2005; 147: 659-663.

[12] Ichimura S, Yoshida K, Sutino AB, Horiguchi T, Kawase $T$. Greater petrosal nerve schwannoma-analysis of four cases and review of the literature. Neurosurg Rev 2010; 33: 477-82.

[13] Kumon Y, Sakaki S, Ohta S, Ohue S, Nakagawa K, Tanaka K. Greater superficial petrosal nerve neurinoma. Case report. J Neurosurg 1999; 91: 691-696.

[14] Paulis DD, Cola FD, Marzi S, Ricci A, Coletti G, Galazio RJ. A rare case of greater petrosal nerve schwannoma. Surg Neurol Int 2011; 2: 60 .

[15] Kinouchi H, Milkawa S, Suzuki A, Sasajima T, Tomura N, Mizi K Extradural neuromas at the petrous apex: Report of two cases. Neurosurgery 2001; 49: 999-4.

[16] Moroni AL, Righini C, Faure C, Serra-Tosio G, Lefournier V. CT features of an unusual calcified schwannoma of the superior laryngeal neve. AJNR Am J Neuroradiol 2007; 28: 981-2.

[17] Katoh M, Aida T, Imamura H, Aoki T, Yoshino M, Kashiwazaki D, Takei H. Calcified vestibular schwannoma in the cerebellopontine angle. J Clin Neurosci 2007; 14: 1207-9.

[18] Tosaka M, Hirato J, Miyaqishima T, Saito N, Nakazato Y, Sasaki T. Calcified vestibular schwannoma with unusual histological characteristics-positive immunoreactivity for CD-34 antigen. Acta Neurochir (Wien) 2002; 144: 395-9.

[19] Kleinsasser O, Friedman G. On neurinoma of the nervus facialis. Zentralbl Neurochir 1959; 19: 49-9. 
[20] Tremble E, Penfield W. Operative exposure of the facial canal: with removal of a tumor of the greater superficial petrosal nerve. Arch Otolaryngol 1936; 25: 573-9.

[21] Sade B, Lee JH. Recovery of low-frequency sensorineural hearing loss following resection of a greater superficial petrosal nerve schwannoma: case report. J Neurosurg 2007; 107: 181-4.
[22] Umredker A, Singla N, Gupta SK, Radotra B. Greater superficial petrosal nerve schwannoma: report of 2 cases and literature review. Neurol India 2011; 59(5): 786-8.

Received: November 25, 2014

Revised: February 12, 2015

Accepted: February 13, 2015

(C) Ansari et al.; Licensee Bentham Open.

This is an open access article licensed under the terms of the Creative Commons Attribution Non-Commercial License (http://creativecommons.org/licenses/by-nc/3.0/) which permits unrestricted, non-commercial use, distribution and reproduction in any medium, provided the work is properly cited. 